Para enlazar con este artículo / To link to this article:

https://doi.org/10.6035/MonTI.2020.12.05

Para citar este artículo / To cite this article:

Cuéllar Lázaro, Carmen. (2020) "Untertitel für Gehörlose vs. subtitulado para sordos: el reto de hacer visible lo inaudible." En: Richart-Marset, Mabel \& Francesca Calamita (eds.) 2020. Traducción y Accesibilidad en los medios de comunicación: de la teoría a la práctica / Translation and Media Accessibility: from Theory to Practice. MonTI 12, pp. 144-179.

\title{
UNTERTITEL FÜR GEHÖRLOSE VS. SUBTITULADO PARA SORDOS: EL RETO DE HACER VISIBLE LO INAUDIBLE
}

\author{
CARMEN CUÉllar LÁZARO \\ carmen.cuellar@uva.es \\ Universidad de Valladolid
}

\section{Resumen}

El presente estudio tiene como objetivo conocer el tratamiento dado al subtitulado para personas sordas y personas con discapacidad auditiva en lengua alemana (Untertitel für Gehörlose und Hörgeschädigte, UGH) y en español (SPS) a lo largo de las últimas décadas. Para ello se analizará esta modalidad de traducción audiovisual en varias películas producidas entre 1981 y 2018, centrándonos en aquellos parámetros más característicos de este tipo de subtitulado. Desde el punto de vista diacrónico, el análisis nos permitirá ver la evolución que el subtitulado para personas sordas y personas con discapacidad auditiva ha experimentado a lo largo de estos años en cada una de las lenguas. Por otra parte, desde la perspectiva diatópica, observaremos también el comportamiento de esta variante de subtitulado a lo largo de estas décadas en Alemania y España, dos países de tradición dobladora.

Palabras clave: Subtitulado para sordos y personas con discapacidad auditiva; Untertitel für Gehörlose und Hörgeschädigte; Traducción audiovisual; Accesibilidad; Cine accesible. 


\begin{abstract}
"Untertitel für Gehörlose vs. Subtitled for Deaf People: The Challenge of making visible the unaudible"

The present study aims to understand the treatment that has been given to the Subtitling for the Deaf and Hard-of-Hearing in the German language (Untertitel für Gehörlose und Hörgeschädigte, UGH) and in Spanish (SPS) throughout the last decades. To do so, we analyze the modality of audiovisual translation in several films produced between 1981 and 2018, focusing on the parameters most characteristic of this type of subtitling. From the diachronic point of view, the analysis will allow us to see the evolution that Subtitling for Deaf and Hard-of-Hearing people has undergone in each of the languages over these years. On the other hand, we will observe the behavior of this variant of subtitling from a diatopic perspective throughout these decades in Germany and Spain, two countries that traditionally practice dubbing instead of subtitling.
\end{abstract}

Keywords: Subtitling for the Deaf and Hard-of-Hearing; Untertitel für Gehörlose und Hörgeschädigte; Audiovisual translation; Accessibility; Accessible cinema.

\title{
1. Introducción
}

La sociedad actual está cada vez más sensibilizada con la discapacidad y hay una mayor concienciación sobre la necesidad de que la accesibilidad llegue también al ocio y la cultura. Uno de los grupos más importantes en el campo de la discapacidad lo constituyen las personas con discapacidad sensorial, personas con discapacidad visual y/o auditiva ${ }^{1}$. Para que este colectivo pueda tener acceso a los contenidos audiovisuales ha de contar con alternativas

1. El Instituto Nacional de Estadística (INE) contabiliza en España un total de 1.064.000 personas sordas o con algún tipo de discapacidad auditiva (cfr. los datos de la última encuesta del INE, recogidos en su estudio EDAD 2008, Encuesta de Discapacidad, Autonomía personal y situaciones de Dependencia, en el siguiente enlace: <http://www.ine.es/ prensa/np524.pdf>).

Según los datos de la asociación Deutsche Gesellschaft der Hörgeschädigten - Selbsthilfe und Fachverbände e.V, viven en Alemania unos 13 millones de discapacitados auditivos (cfr. el enlace: <http://sign-dialog.de/wp-content/forderungskatalog.pdf>). La asociación Deutscher Gehörlosen Bund eleva la cifra a 16 millones de individuos con algún tipo de discapacidad auditiva, alrededor de 140.000 tienen un grado de discapacidad mayor al $70 \%$ y 80.000 personas son sordos totales. Cfr. la página web de la asociación: <http:// 
al contenido auditivo, lo que sucede, gracias a los subtítulos y al contenido visual, mediante la audiodescripción. En lo que respecta al sector audiovisual, al consumo clásico de la televisión, el cine, el teatro y los museos se suma el uso de audiovisuales a través de Internet en diversos formatos y desde distintos dispositivos: tabletas, móviles, ordenadores, Smart TV, etc. En definitiva, en la sociedad actual cada vez se consumen más contenidos audiovisuales y multimedia y los posibles entornos de aplicación y empleo traspasan las tradicionales actividades culturales.

A través de la presente investigación conoceremos la evolución del SPS en alemán y en español a lo largo de los últimos años partiremos del análisis de los parámetros que caracterizan este tipo de subtitulado. Además, desde una perspectiva diatópica, observaremos el comportamiento de esta modalidad de subtitulado en Alemania y España, dos países acostumbrados a consumir los productos audiovisuales doblados.

\section{La accesibilidad en el contexto audiovisual en España: El caso del SPS}

Los primeros subtítulos dirigidos a la comunidad sorda se emitieron en la televisión pública americana PSB (Public Service Broadcasting) en 1973. En Europa, la BBC (British Broadcasting Corporation) marcó el camino en 1979 emitiendo el primer programa subtitulado para sordos; en otros países europeos, los primeros subtítulos para sordos llegaron a lo largo de los años ochenta y noventa. En España, la cadena pionera en la emisión de subtítulos para sordos fue la CCRTV (Corporación Catalana de Televisión) en 1990 y unos meses después le siguió TVE (Televisión Española). En estos primeros años, sin embargo, la oferta de programas de subtitulado era muy reducido y los subtítulos se emitían solo de manera ocasional, no existiendo otras iniciativas que facilitaran a las personas con discapacidad auditiva el acceso a los medios audiovisuales. Será con el cambio de siglo cuando se impulse un camino hacia la accesibilidad (Pereira 2005: 163-164). ${ }^{2}$ En 2001

gehoerlosen-bund.de/>. Cfr. asimismo Hellebrand 2007: 6-8, quien analiza la dificultad en el cómputo de este tipo de discapacidad, dada la heterogeneidad del colectivo.

2. En Cuéllar Lázaro (2016a: 145-149) se recogen fechas clave en España en el avance hacia la accesibilidad del colectivo con discapacidad auditiva. Sobre la evolución del 
se aprueba la Ley de Fomento y Promoción de la Cinematografía y el sector Audiovisual (España. Ley 15/2001), en la que se especifica el compromiso con la eliminación de las barreras de comunicación que dificulten el acceso a obras audiovisuales por parte de personas con discapacidad sensorial ${ }^{3}$. Un punto de inflexión en el marco de Europa fue la celebración en 2003 del Año Europeo de las personas con discapacidad. En este contexto se aprueba en España la Ley 51/2003, de 2 de diciembre, de igualdad de oportunidades, no discriminación y accesibilidad universal de las personas con discapacidad. Ese mismo año se publica la norma UNE 153010 de 2003: Subtitulado para personas sordas y personas con discapacidad auditiva. Subtitulado a través del teletexto, elaborada por la Asociación Española de Normalización y Certificación (AENOR), que fue anulada y sustituida por la norma de 2012 Subtitulado para personas sordas y personas con discapacidad auditiva. Esta última tiene un carácter más general y contempla todos los escenarios de la comunicación audiovisual con el objetivo de establecer unos requisitos mínimos de calidad y homogeneidad en el subtitulado ${ }^{4}$.

El porcentaje de contenidos subtitulados en televisión se acerca ya al 100\%, como muestran los datos del Centro Español del Subtitulado y la Audiodescripción (CESyA), desde donde se realiza un seguimiento diario de los servicios de subtitulado y audiodescripción en la TDT (imagen 1): ${ }^{5}$

\section{SUBTITULADO}

Datos obtenidos el: 17/04/2019

\begin{tabular}{|c|}
\hline Porcentaje subtitulado \\
$88.57 \%$ \\
\hline
\end{tabular}

Programas subtitulados

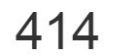

Imagen 1. Seguimiento del subtitulado en televisión

El reto actual es promover y fomentar que el subtitulado que se ofrece sea de calidad; para ello se creó el CESyA, un centro técnico de referencia en materia de accesibilidad audiovisual para personas con discapacidad en lo referente a

SPS en España cfr., entre otros, CESyA (2014), Lorenzo \& Pereira (2012), Utray et al. (2009), Neves \& Lorenzo 2007, Izard 2001; Pardina 1998 y 2000. 
la producción, distribución y exhibición de obras cinematográficas y audiovisuales (España. Ley 27/2007). Este organismo expide una Certificación de la accesibilidad audiovisual de entidades, espacios y productos audiovisuales y culturales a través del Sello CESyA como marca de garantía que valida y asegura las buenas prácticas en el ejercicio del subtitulado y la audiodescripción ${ }^{6}$.

Para conseguir la calidad deseada es fundamental la investigación y la formación en el campo de la accesibilidad, teniendo presente además la transversalidad de las disciplinas implicadas ${ }^{7}$. En este contexto, en 2019 se publica el Real Decreto 94/2019 por el que se establece el Curso de especialización en audiodescripción y subtitulación y se fijan los aspectos básicos del currículo (pp. 29700-29729). Para su elaboración fueron consultadas las Comunidades Autónomas, así como el Consejo Nacional de la Discapacidad (CND). ${ }^{8}$ En efecto, una de las funciones del CND es impulsar actividades de investigación, formación, innovación, ética y calidad en el ámbito de la discapacidad.

Este real decreto tiene por objeto el establecimiento del Curso de especialización de formación profesional en audiodescripción y subtitulación, con carácter oficial y validez en todo el territorio nacional, así como de los correspondientes aspectos básicos del currículo (España. Real Decreto 94/2019: 29701).

Es preciso destacar algunos aspectos de este curso de especialización. En primer lugar, que se identifica para todo el territorio nacional a nivel de "Formación Profesional de Grado Superior", es decir, tiene un carácter fundamentalmente técnico. Asimismo, involucra distintas ramas de conocimiento: Artes y Humanidades, Ciencias Sociales y Jurídicas, Arquitectura e Ingeniería,

6. Dos de las películas que han servido para el análisis en la parte aplicada de este estudio llevan este sello, ambas de 2017: El malvado zorro feroz y Dos mujeres.

7. Cfr. en Cuéllar Lázaro 2016a un estudio sobre la situación de la formación universitaria en accesibilidad tanto en España como en Alemania. Cfr. asimismo Díaz Cintas 2007 y Díaz Cintas et al. 2007.

8. El CDN es un órgano consultivo interministerial a través del cual las organizaciones representativas de personas con discapacidad, así como sus familias participan en la planificación, el seguimiento y la evaluación de las políticas que se desarrollan en el ámbito de la discapacidad. Está regulado por el Real Decreto 1855/2009, disponible en: <https://www.mscbs.gob.es/ssi/discapacidad/informacion/consejoNacionalDisc.htm> 
poniendo en valor el carácter transversal de esta formación (p. 29702) ${ }^{9}$. Por último, se especifica con detalle el perfil profesional del egresado, que podrá ejercer su actividad, en lo que respecta al tema que nos ocupa, como "Subtitulador/a de obras audiovisuales y espectáculos en vivo y eventos" y "Revisor/a de subtítulos" (p. 29703).

El mercado de la accesibilidad a los contenidos audiovisuales sigue creciendo en España y se necesitan profesionales formados para dar este servicio $^{10}$. Por ello, invertir en investigación y en formación de los subtituladores es uno de los retos a los que se enfrenta la sociedad en el campo de la accesibilidad. Estos profesionales son una pieza esencial para conseguir la calidad deseada.

El 14 de febrero de 2019, el Comité Español de Representantes de Personas con Discapacidad (CERMI) reclamó al Congreso de los Diputados una regulación legal exigente de la accesibilidad al cine. ${ }^{11}$ Entre las medidas necesarias, el CERMI plantea como requisito imprescindible para recibir ayudas públicas que las nuevas producciones se comprometan a incorporar requisitos de accesibilidad. La Ley de Cine de 2007 ya establecía ayudas con objeto de subvencionar hasta el 50 por 100 del coste del tiraje de copias, del subtitulado, de la publicidad y promoción, de los medios técnicos y de los recursos necesarios para el acercamiento de las películas a colectivos con discapacidades (art. 28). El 12 de abril de 2019 se publica la última modificación a esta ley y se establecen las Ayudas a la distribución en soporte videográfico o a través de internet en estos términos:

Se podrán convocar ayudas a la distribución en soporte videográfico o a través de internet siempre que se incorporen sistemas de audiodescripción para personas ciegas y con discapacidad visual y sistemas de subtitulado especial y lengua de signos para personas sordas y con discapacidad auditiva,

9. En la descripción del curso se le asignan 30 créditos ECTS, aunque se indica a su vez que cubre 500 horas de formación (p. 29702).

10. La página web del CESyA informa de una veintena de empresas que ofrecen servicios de subtitulación y trece de audiodescripción, cfr. <http://www.cesya.es/recursos/ empresas>

11. Cfr. Discapnet, El portal de las Personas con Discapacidad, Fundación ONCE <https://www.discapnet.es/actualidad/2019/02/el-cermi-reclama-al-congresouna-regulacion-legal-exigente-de-la-accesibilidad-al> 
con las condiciones y requisitos que se establezcan en cada convocatoria.

(España. Orden CUD/426/2019, art. 46)

Asimismo, como se observará a continuación en la normativa alemana, se aboga por aunar los procesos de producción y traducción, solicitando que la legislación recoja la obligatoriedad de que las producciones cinematográficas y audiovisuales incluyan, en origen, como medidas de accesibilidad en el cine, la subtitulación, la lengua de signos española y la audiodescripción (AD). Fomentar el cine accesible implica integrar la traducción audiovisual (TAV) y la accesibilidad en el proceso de realización de un producto cinematográfico. Lo ideal sería no limitar la idea al SPS y la AD, sino a la TAV en general, puesto que traducir una película es también hacerla accesible a los espectadores de otras lenguas (Romero-Fresco 2015). ${ }^{12}$

\section{La accesibilidad en el contexto audiovisual en Alemania. El caso del UGH}

En el contexto alemán fue la cadena ARD (Arbeitsgemeinschaft der öffentlich-rechtlichen Rundfunkanstalten der Bundesrepublik Deutschland) la primera en emitir la modalidad de subtitulado en 1980 (Rüngs 2006: 48 y Hellebrand 2007: 17). Sin embargo, en 2008, casi 30 años después, las asociaciones alemanas de discapacitados auditivos, Deutscher Gehörlosen Bund e.V. presentan un estudio en el que se pone de manifiesto la baja cuota de subtitulado en las cadenas públicas, prácticamente inexistente en el caso de las cadenas privadas, y su evolución en el periodo de 2005 a 2011: las dos cadenas públicas a nivel nacional, ZDF y ARD, ascienden del 18,4\% y 16,3\% respectivamente en 2005, al 38,9\% (ZDF) y 36,7\% (ARD) en 2011. Con respecto a las cadenas privadas, las que ofrecen mayor contenido son Pro7, con un 1,4\% en 2005 que evoluciona a un 13,3\% en 2011, y Kabel, que en este mismo periodo se incrementa del 2,1\% al 4,7\% (Schneider, 2011).

El año 2013 supuso un cambio importante hacia una mejora en el campo de la accesibilidad en Alemania. A partir del 1 de enero de ese año entra en vigor la nueva ley de radiodifusión Rundfunkbeitragsrecht, que obligaba

12. Cfr. otros estudios recientes sobre accesibilidad, entre ellos, Matamala y Orero, 2010; Romero-Fresco, 2011, Lorenzo y Pereira, 2011; Remael et al. 2012, Arnáiz Uzquiza, 2012, Szarkowska et. al., 2013 y Talaván et al. 2016. 
también a las personas con discapacidad al pago de la tarifa de radiodifusión ${ }^{13}$. En este contexto, la asociación de sordos Deutsche Gehörlosenverband exigió a los medios públicos avanzar en el camino de la accesibilidad y su compromiso de ofrecer un $100 \%$ de la programación subtitulada. ${ }^{14}$ La televisión pública reconoce en la actualidad este compromiso:

Da auch Menschen mit Behinderung anteilig einen Rundfunkbeitrag zahlen, steht das Thema Barrierefreiheit stark im Fokus: So untertitelt die ARD 95 Prozent der Sendungen in „Das Erste“. Beim ZDF ist zwischen 16 und 22.15 Uhr das komplette Programmuntertitelt, [...] Unser Ziel ist der Ausbau zu einem 100 Prozent barrierefreien Programm ${ }^{15}$.

En 2018, el 98\% de la oferta de la televisión pública se emitía en subtitulado para discapacitados auditivos, tal y como se recoge en el siguiente gráfico (imagen 2): ${ }^{16}$

13. Cfr. la repercusión de esa ley para las personas con discapacidad en el siguiente informe elaborado por la asociación Sozialverband Deutschland: <https://www. sovd.de/fileadmin/downloads/pdf/sonstiges/Flugblatt_Rundfunkbeitrag_web.pdf>

Esta ley ha sido modificada en 2017. Cfr. en el siguiente enlace de la cadena pública Das Erste un video en el que se muestra cómo se elaboran los subtítulos en directo: $<$ https://www.daserste.de/unterhaltung/interviews-extras/videos/so-entsteht-dielive-untertitelung-100.html>

14. Cfr. esta resolución a favor de una televisión sin barreras (Resolution für barrierefreies Fernsehen), en línea: <http://www.gehoerlosen-bund.de/>

15. Cfr.<https://www.rundfunkbeitrag.de/der_rundfunkbeitrag/senderfamilie/index_ger. html?highlight=untertitelt\%2C\%20untertitelt\#grund_barrierefrei> Cfr. asimismo Hezel, 2009: 147, Melgarejo Weinandt, 2005 y Nagel 2009. En el caso de la audiodescripción, el porcentaje es del 49,50 \% de los programas principales de la sesión de tarde. Cfr. la página web de la cadena pública Das Erste en: <https://www.daserste.de/ specials/service/barrierefreie-angebote-ard100.html>

16. Fuente: Cadena estatal ARD <http://www.ard.de/home/die-ard/fakten/Barrierefreie_ Angebote_der_ARD/4036078/index.html> 


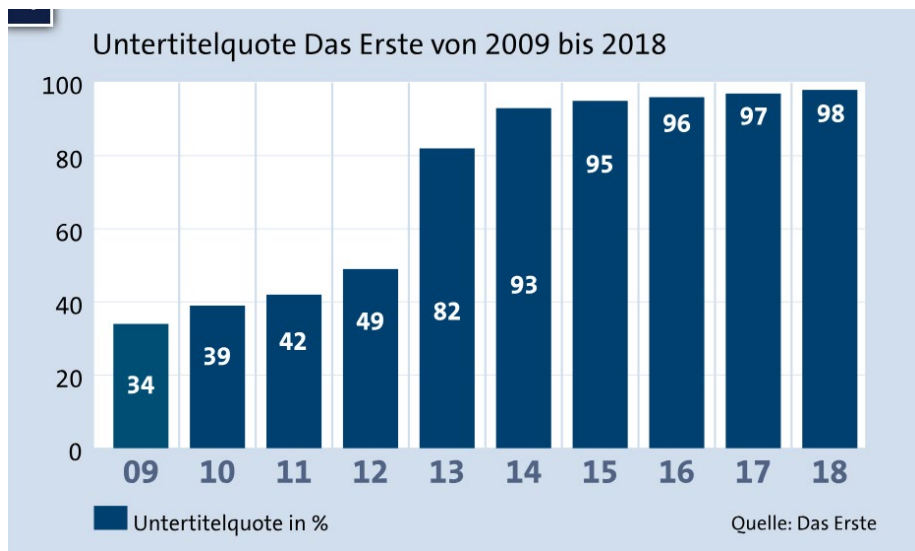

Imagen 2: Porcentaje de subtitulado en la cadena pública alemana Das Erste.

El 21 de septiembre de 2018, varias asociaciones alemanas (Verbändebündnis der Zivilgesellschaft, Deutscher Behindertenrat, Bundesarbeitsgemeinschaft der Freien Wohlfahrtspflege, Fachverbände für Menschen mit Behinderung y Liga Selbstvertretung) presentaron un manifiesto en Ginebra, durante una reunión con el Comité de Expertos en Discapacidades de las Naciones Unidas, en el que destacaban el agravio comparativo de la situación de las personas con discapacidad auditiva en el acceso a la información en Alemania. Reconocen que ha habido un desarrollo positivo en la televisión pública en los últimos años, ya que por ley está obligada a la accesibilidad; sin embargo, en la privada, solo el 9-13\% de los programas están subtitulados.

Es gibt in Deutschland einen Zwei-Klassen-Zugang zu Informationen, weil der private Rundfunk nicht zur Barrierefreiheit verpflichtet ist. Beim öffentlich-rechtlichen Fernsehen gab es in den letzten Jahren eine positive Entwicklung. Im privaten Fernsehen sind nur 9-13\% der Sendungen mit Untertiteln versehen. ${ }^{17}$

Efectivamente, en el caso de la televisión privada, el porcentaje de subtitulado sigue siendo en 2019 muy bajo, pese a que desde la asociación de medios privados VAUNET (Verband Privater Medien) se subraye el avance

17. Cfr. <http://www.gehoerlosenbund.de/gesetze/behindertenrechtskonvention> 
hacia la accesibilidad con este titular en su página web: "Barrierefreiheit im Privatfernsehen: immer mehr Shows und Sportsendungen untertitelt" (03.04.2019). Sin embargo, la noticia deja a la vista unos datos totalmente insuficientes para este colectivo de discapacitados:

Besonders hoch ist der Anteil mit 23 Prozent beim Sender VOX [...]. Bei Sendern der Gruppe ProSiebenSat.1 Media SE werden bereits durchschnittlich 18 Prozent des Angebots untertitelt. Deutlich zugelegt hat ProSieben - der Sender liegt mit 37 Prozent Untertitelung [...] ganz vorn. Die RTLGruppe hat mit durchschnittlich 13 Prozent ihre Programmfläche mit speziellen Untertiteln für Hörgeschädigte ihr Angebot weiter erhöht. ${ }^{18}$

En el ámbito cinematográfico, la nueva ley para la promoción del cine alemán, Filmförderungsgesetz (FFG), que entró en vigor el 1 de enero de $2014^{19}$, fomenta que las películas de producción alemana cuenten con una versión en audiodescripción y otra en SPS en alemán. Para ello, el 50\% de las inversiones en cines relacionadas con la producción de accesibilidad están subvencionadas por la Deutschen Filmförderungsanstalt, FFA (cfr. Cuéllar Lázaro 2016a: 152). En 2017 se modifica de nuevo esta ley y se indica que solo las salas de cine que incluyan posibilidades técnicas para poder proyectar una versión del producto cinematográfico de manera accesibles podrán recibir financiación. La novedad en esta actualización con respecto a la de 2014 es que se hace hincapié en la calidad del producto accesible: "Wenn barrierefreie Fassungen in geeigneter Weise und in angemessenem Maße zugänglich gemacht werden", es decir, la financiación solo se otorgará si las versiones se hacen accesibles de una manera apropiada y en un grado razonable. En este sentido, en julio de 2017, la FFA publicó unas "Recomendaciones para los estándares de producción de películas accesibles", fruto de un grupo de trabajo compuesto por representantes de la industria del cine y los colectivos afectados, con el fin de armonizar las especificaciones técnicas ${ }^{20}$. Sin embargo, la asociación

18. Cfr.<https://www.vau.net/barrierefreiheit/content/barrierefreiheit-privatfernse hen-immer-mehr-shows-sportsendungen $>$

19. La ley del 24 de agosto de 2004 fue modificada el 3 de agosto de 2013. Cfr. esta ley y los cambios que ha sufrido desde su primera publicación en < https://www. buzer.de/ sl.htm?g=FFG+2004\&f $=1>$

20. Cfr. estas recomendaciones en la página web de la FFA: <https://www.ffa.de/ barrierefreiheit.html> 
alemana de discapacitados auditivos Deutscher Gehörlosen-Bund e. V. pone de manifiesto en un comunicado del 29 de marzo de 2019 que hay opiniones muy diferentes sobre lo que se entiende por "apropiado" y "razonable" en referencia a la calidad del producto ${ }^{21}$.

En la práctica habitual, en los dos países aquí analizados, las películas rara vez se emiten con subtítulos abiertos (fijados en la imagen), de tal manera que un espectador con discapacidad auditiva depende de ayudas técnicas, como un teléfono inteligente o gafas de subtítulo ${ }^{22}$. A esto habría que sumar la escasa información sobre las obras con modalidad accesible, así como las salas de proyección que ofrecen cine sin barreras. Precisamente, facilitar la información sobre las películas con modalidad accesible, así como las salas de proyección que ofrecen cine sin barreras, es una de las reivindicaciones de este colectivo ${ }^{23}$.

Los espectadores con discapacidad auditiva ven en los subtítulos abiertos la solución ideal, ya que no tienen que preocuparse por el equipo técnico. Sin embargo, en este comunicado expresan que son conscientes de que hay espectadores (sin problemas de audición) que pueden sentirse perturbados por los subtítulos abiertos. En este sentido, abogan por fomentar el compromiso de que las salas de cine muestren una película con subtítulos abiertos un día a la semana y, durante el resto de la semana, se ofrezca al espectador una solución

21. Asimismo, se aboga por un ajuste en los estándares de los subtítulos teniendo en cuenta el formato en el que se distribuyen las obras, ya sea en la proyección de una sala de cine, o bien en otros formatos como DVD, Internet y televisión. Cfr. el documento en el siguiente enlace: <http://www.gehoerlosen-bund.de/gesetze/bundesbeh. gleichstellungsgesetz>

22. Las nuevas tecnologías están facilitando la accesibilidad en el cine. En el ámbito de la lengua alemana existen desde 2013 las aplicaciones para Apple iOS y Android con el nombre GRETA \& STARKS que hacen llegar la versión subtitulada (STARKS) y la audiodescripción (GRETA) al espectador a través su propio teléfono inteligente. De esta manera, no es necesario que las salas de cine ni el consumidor tengan que invertir en tecnología o equipamiento <http://www.gretaundstarks.de/greta/branche>

23. En España, el CESyA ofrece una Agenda cultura accesible en la que se recoge información sobre cine, teatro, museos y otros eventos que se ofertan en formato accesible. En el caso del cine, se incluye un listado de filmes con audiodescripción a la que se puede acceder en cualquier momento previa descarga en el dispositivo móvil (a través de la app Audescmobile disponible para IOS y Android) < http://www.culturaaccesible. es/cineaudesc.php? provincias=0\&accesibilidad=Todas $>$ 
técnica (sistemas de subtitulación optativa, gafas de datos, bucle magnético). En definitiva, este colectivo subraya la necesidad de mejorar la calidad de los subtítulos y la definición de lo que se entiende por cine accesible.

\section{De Lili Marleen (1981) a Campeones (2018): el subtitulado en las películas analizadas}

En este apartado se lleva a cabo un análisis descriptivo de carácter cualitativo del subtitulado para personas sordas y personas con discapacidad auditiva en lengua alemana (Untertitel für Gehörlose und Hörgeschädigte, UGH) y en español (SPS) en películas producidas entre 1981 y 2018. Las obras cinematográficas pertenecen a distintos géneros y van dirigidas tanto a un público infantil y juvenil como a espectadores adultos. Al final de este estudio se recoge el total de las películas analizadas. Puede ser ilustrativo el hecho de que en la búsqueda de subtítulos para personas sordas en alemán y en español solo se encontrara esta modalidad de subtitulado en ambos idiomas en una de ellas: Lili Marleen (1981). No obstante, hay que tener en cuenta que no hay uniformidad en la caracterización de los DVD y que se buscaba la modalidad "para sordos". Se ha hallado esta especificidad dentro del apartado "Subtítulos": "Castellano para Sordos", "Alemán para Sordos", pero también (sobre todo en los DVD más recientes) fuera del epígrafe "Subtítulos", como un tercer apartado, "Codificado para Sordos: Alemán", "Codificado para Sordos: Castellano", diferenciándolo de los epígrafes "Audio" y "Subtítulos". En otros DVD se omite el término "sordos" y se especifica la modalidad como "Castellano para personas con discapacidad auditiva". ${ }^{24}$

Asimismo, desde el punto de vista metodológico nos centramos en aquellos parámetros que caracterizan este tipo de subtitulado y que son de mayor interés para el análisis, basándonos en la norma española UNE 153010:2012. En el caso de Alemania, no existe una norma estandarizada y se han consultado las distintas directrices para el subtitulado elaboradas por

24. Las películas se han conseguido a través de la Biblioteca pública de la Comunidad de Castilla y León con su sede en Valladolid, que cuenta con un total de 17.251 obras audiovisuales en su catálogo. Desde aquí expresamos nuestro agradecimiento al Servicio de Audiovisuales de esta biblioteca por la ayuda prestada para llevar a cabo esta investigación. 
varias instituciones, entre ellas, las recomendaciones de la FFA de las que hemos hablado ya en este estudio (a partir de ahora nos referiremos a ellas como FFA2017) y las directrices de instituciones públicas alemanas de radiodifusión que han elaborado unos estándares para países de habla alemana (MDR2018 y MDR2015) ${ }^{25}$. Estas directrices vienen a ampliar las recomendaciones elaboradas por varias asociaciones de discapacitados auditivos, tanto de Alemania como de Austria y Suiza, para la armonización de subtítulos en 2013, Gemeinsame Untertitelrichtlinien für den deutschen Sprachraum (UT2013). ${ }^{26}$

Para cada una de las obras cinematográficas hemos elaborado la siguiente ficha, en la que se presentan los parámetros analizados, estructurados en cuatro apartados (imagen 3). En primer lugar, se observa la presentación del subtítulo, es decir, la posición en la pantalla, el número de líneas de texto y el número de caracteres por línea. A continuación, se analiza la manera de identificar a los personajes, ya sea mediante color, etiquetas, guiones, así como la marcación de la voz en off. En tercer lugar, se comprueba si en los subtítulos se transcriben otros sonidos, como son los efectos sonoros, la música y las canciones y, en el caso de estas últimas, qué información aparece para identificarlas, si se transcribe el texto de la canción y cómo se indica (mediante almohadilla, nota musical, cursiva, etc.). Por último, se averigua si el subtítulo aporta otra información relevante, como la información contextual o la indicación de otras lenguas en la película.

25. En abril de 2018 la empresa pública de radiodifusión Mitteldeutscher Rundfunk publica la cuarta edición de las directrices para la subtitulación en $<$ https://www. mdr.de/unternehmen/ausschreibungen/richtlinien-mdr-untertitelung-100.html> Cfr. igualmente https://www.ndr.de/fernsehen/service/untertitel/Untertitel-Standards, untertitelstandards102.html>.

26. Se puede consultar el documento en: http://www.untertitelrichtlinien.de/index.html> Cfr. una comparación de las directrices de subtitulado en Alemania, Austria y Suiza en Méan 2011; cfr. asimismo Panier 2012. 


\begin{tabular}{|c|l|l|}
\hline \multirow{4}{*}{ Presentación del subtítulo } & Posición de los subtítulos & \\
\cline { 2 - 3 } & Posición de los efectos sonoros & \\
\cline { 2 - 3 } & Número de líneas de texto & \\
\hline & Número de caracteres por línea & \\
\hline \multirow{4}{*}{ Identificación del personaje } & Color & \\
\cline { 2 - 3 } & Etiquetas & \\
\cline { 2 - 3 } & Guiones & \\
\hline & Ooz en off & \\
\hline \hline \multirow{2}{*}{ Otros sonidos } & Efectos sonoros & \\
\hline & Música & \\
\hline & Canciones & \\
\hline \hline \multirow{2}{*}{ Otra información } & Información contextual & \\
\hline & Otras lenguas & \\
\hline
\end{tabular}

Imagen 3: Ficha modelo para el análisis (elaboración propia).

Por otra parte, cuando el original sea en otra lengua distinta al alemán o al español, la traducción en el subtítulo será interlinguística, es decir, traducción propiamente dicha. Sin embargo, en otras películas será intralingüística, al tratarse de la misma lengua. En los siguientes apartados presentamos el resultado del análisis según el orden marcado por la ficha de trabajo.

\subsection{Presentación del subtítulo}

En referencia a la posición de los subtítulos, a lo largo del análisis se constata que, en líneas generales, estos aparecen centrados en la parte inferior de la pantalla, a no ser que, condicionados por la imagen, se prefiera excepcionalmente en la parte superior, como en la imagen 4, en la que la información paratextual en inglés se indica así en alemán para no coincidir con la imagen del paratexto. Si esto sucede, la lectura del subtítulo puede verse dificultada (imagen 5): 

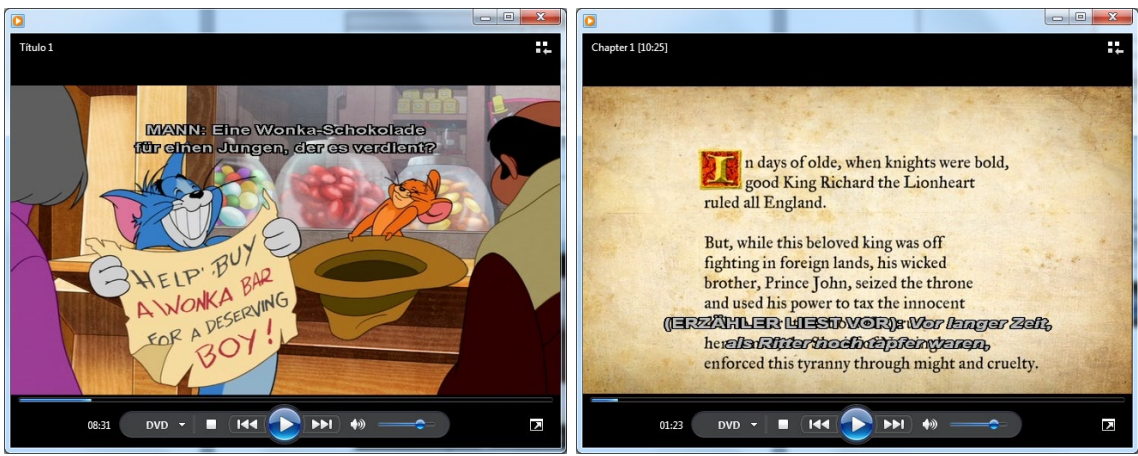

Imagen 4: Tom y Jerry: Charlie y la Fábrica de Chocolate (2017) Imagen 5: Tom y Jerry: Robin Hood y el ratón de Sherwood (2012)

Se ha observado una diferencia por países en la posición de los subtítulos que muestran los efectos sonoros, como veremos más adelante en el apartado dedicado a este parámetro. En las películas analizadas con la modalidad UGH alemán, cuando se marcan los efectos sonoros, estos aparecen centrados en la parte inferior de la pantalla, como el resto de subtítulos (imagen 18). También en las obras con SPS español, las anteriores a la norma UNE 153010: 2012, lo marcan con subtítulos centrados en la parte inferior de la pantalla, como se ve en Chicken Run: Evasión en la Granja (2000) (imagen 19); sin embargo, las más recientes suelen ubicarlo en la parte superior derecha, tal y como indica la norma (imágenes 20 y 21 ).

Con respecto al parámetro relacionado con el número de líneas de texto, se respeta el máximo de dos líneas por subtítulo y un límite de 37 caracteres por línea que marcan la norma UNE 153010:2012 en España (p. 9), así como las directrices recogidas en UT2013 y MDR2015 en Alemania: "In einer Zeile werden maximal 37 Zeichen genutzt"27, aunque hay subtítulos en ambos idiomas al límite de caracteres en las dos líneas (imágenes 6 y 7), con la dificultad que esto supone para la comprensión lectora de las personas sordas (Cambra 2008-2009: 156, Cambra 2013: 105-106, Torres Monreal 2005 y FIAPAS 2013: 22-24). 

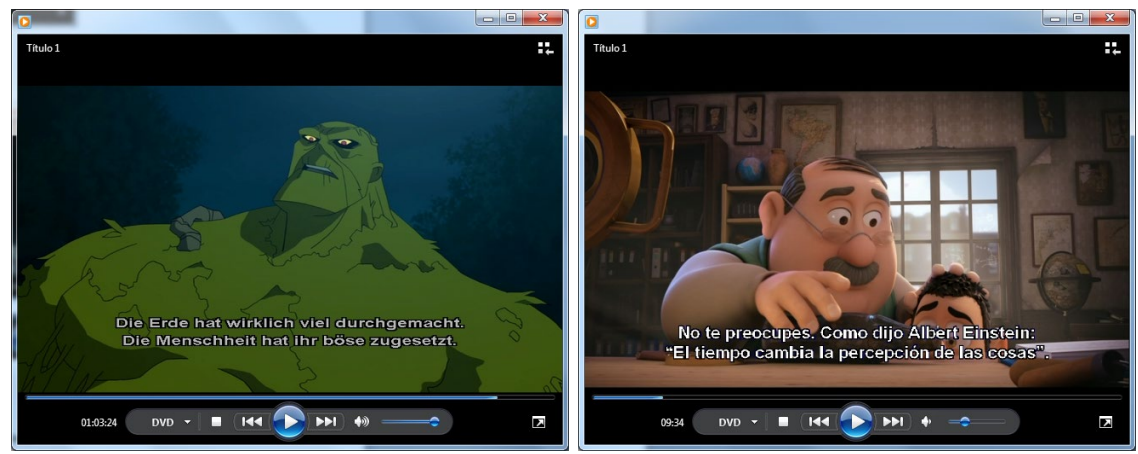

Imagen 6: Batman y Harley Quinn (2017)

Imagen 7: Las aventuras de Tadeo Jones (2012)

\subsection{Identificación de los personajes}

La identificación de los personajes es fundamental para facilitar el seguimiento de la trama argumental de los contenidos audiovisuales, de ahí la importancia de este parámetro. La norma UNE 153010:2012 recoge tres técnicas de identificación con el siguiente orden en la prioridad de uso: color, etiquetas y guiones. Todas las películas analizadas con SPS español emplean el color para identificar a los personajes. aunque, como veremos a continuación, en el caso de las producidas con posterioridad a esta norma, no todas siguen sus directrices: que el personaje con mayor carga se identifique con color amarillo, dejando el cian, magenta y verde para diferenciar a otros personajes principales, y el resto de personajes, así como el resto de información (efectos sonoros, información contextual, canciones, etc.), en color blanco.

La película El increíble Hulk (2008), subtitulada por la Confederación Española de Familias de Personas Sordas (FIAPAS), aclara al comienzo de la película los colores que identifican a los distintos personajes, así como los efectos sonoros (imágenes 8 y 9 ): 28

28. En la norma UNE 153010:2003 se asignaba el color azul para canciones y efectos sonoros, aunque se especificaba que estos últimos podían ir también en rojo (p. 7). 

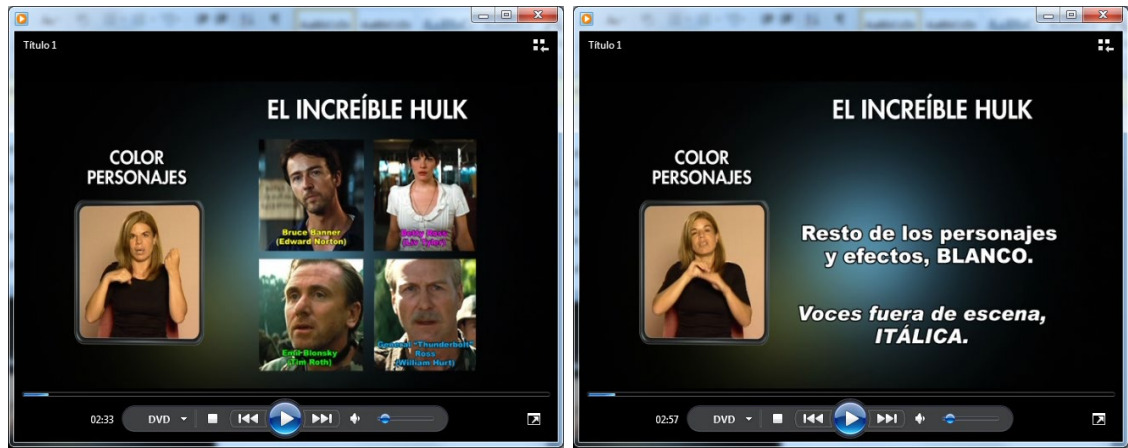

Imágenes 8 y 9: El Increíble Hulk (2008)

Cuando a través de la imagen se observa quién habla, suele identificarse al personaje solo con el color, sin embargo, en el caso de duda (porque hablen varios personajes a la vez, no se vea la boca del que habla, o sea voz en off), se hace uso de etiquetas o guiones para evitar confusiones (imágenes 10 y 11$)$ :
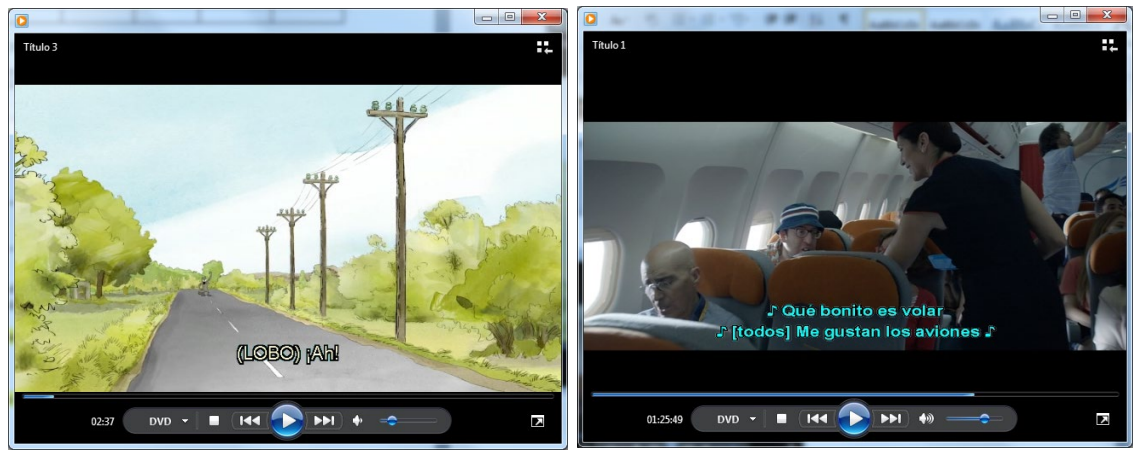

Imagen 10: El malvado zorro feroz (2017)

Imagen 11: Campeones (2018)

Llama la atención que la película más actual de las analizadas, Campeones (2018), con una temática dirigida a concienciar al espectador de las dificultades 
diarias de los discapacitados, solo emplee dos colores para identificar a los personajes en el subtitulado: el blanco y el cian. Asimismo, un mismo personaje, el entrenador de baloncesto del grupo de jóvenes con discapacidad, unas veces se identifica con el color blanco y otras con el cian. Incluso en la misma imagen aparecen dos intervenciones de distintos personajes en el mismo color, sin etiquetas ni guiones, lo que puede inducir a error.

En las películas con la modalidad de subtitulado UGH alemán, se prescinde del color para distinguir entre los personajes, de tal manera que todo el subtitulado se presenta en color blanco. ${ }^{29} \mathrm{La}$ única película de las analizadas que hace uso del color para identificar a los personajes es Lili Marleen. La película fue producida en 1981 y el DVD con el que hemos trabajado recoge la versión doblada en alemán y en español, así como el subtitulado en estos dos idiomas y el subtitulado para sordos también en ambos. A través del análisis se ha observado que el subtitulado para oyentes, tanto en el caso de la lengua alemana como de la española, sirve de base para la modalidad de subtitulado para discapacitados auditivos, de tal manera que la única diferencia es que se han marcado con colores las intervenciones de los distintos personajes. Es decir, a lo largo de la película no se describen elementos narrativos no verbales, como los efectos sonoros, ni la información contextual.

En el resto de obras con subtitulado UGH alemán se emplea solo el color blanco y se hace uso de las etiquetas y los guiones únicamente para evitar confusiones, porque no se ve en la imagen quién habla (imagen 12) o para incluir en la misma escena información contextual y diálogo (imagen 13). 

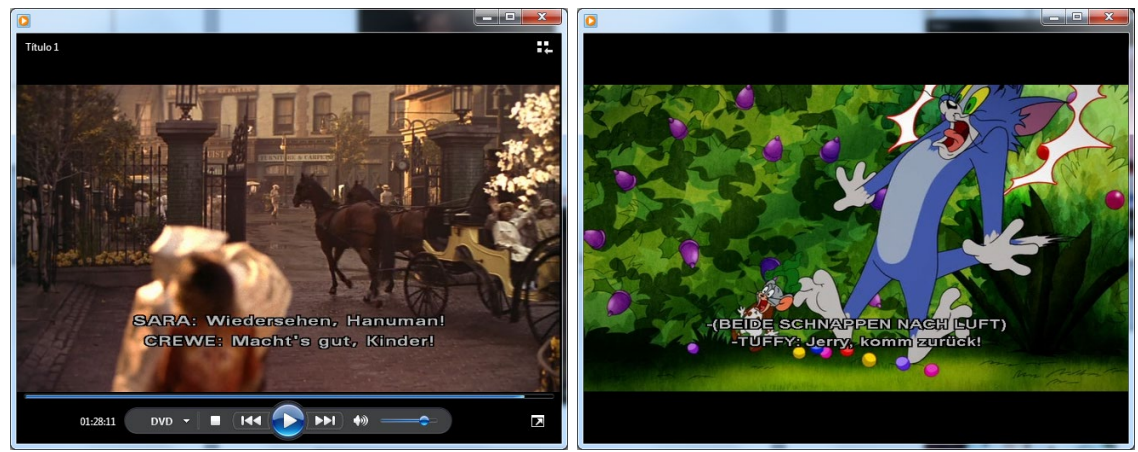

Imagen 12: La princesita (1995)

Imagen 13: Tom y Jerry: Charlie y la Fábrica de Chocolate (2017)

Precisamente con respecto a este último parámetro, la voz fuera de escena, denominada voz en off, el tratamiento que se marca por norma en España es la cursiva (UNE 153010:2012: 14), y esto suele coincidir en la mayoría de las películas, también en las que se especifica el subtitulado UGH alemán (imágenes 14 y 15).
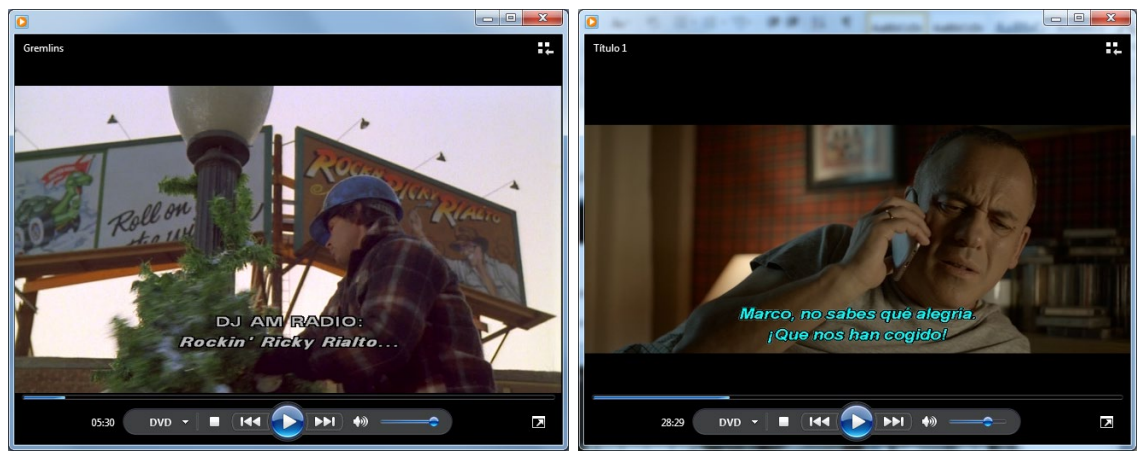

Imagen 14: Gremlins (1984) Imagen 15: Campeones (2018)

Sin embargo, se observan además otras estrategias a la hora de marcar la voz fuera de escena: en Lili Marleen (1981) se emplea el color naranja (tanto en el subtitulado UGH alemán como en el SPS español) en lugar de la cursiva, 
coincidiendo con el color que se emplea para la identificación de personajes con menos cantidad de intervención en el subtitulado de ambos idiomas. En otros casos se marca la voz en off sin cursiva y entre corchete angular (La gran aventura de Mortadelo y Filemón, 2003, imagen 16) o añadiendo la etiqueta "off" entre corchetes al introducir la intervención (Las aventuras de Tadeo Jones, 2012, imagen 17).
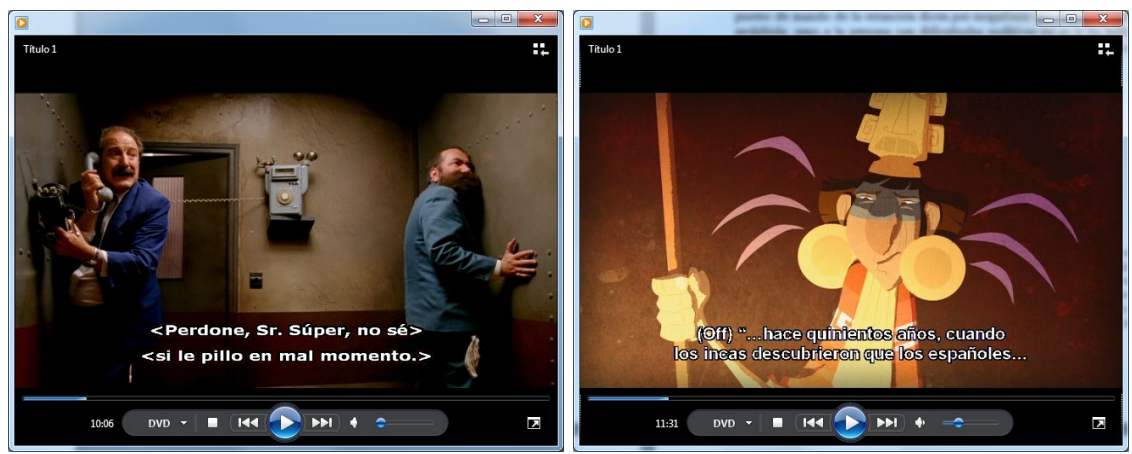

Imagen 16: La gran aventura de Mortadelo y Filemón (2003) Imagen 17: Las aventuras de Tadeo Jones (2012)

Se observa, por lo tanto, la falta de unanimidad también en este parámetro.

\subsection{Otros sonidos}

En este apartado analizamos otro tipo de sonidos que aparecen en la obra audiovisual generalmente fuera del diálogo: Los efectos sonoros, la música y las canciones.

Comenzamos definiendo el parámetro "efecto sonoro" como un sonido no vocal y vocal (exceptuando el habla) que aporta información relevante para el seguimiento de la obra audiovisual, pero no se puede atribuir a un personaje concreto (UNE 153010:2012: 13). El efecto sonoro puede ser producido por cualquier persona o cosa que aparezca en la película, tanto en la pantalla como fuera de ella, y se subtitulará si no es evidente que se ha producido. Por el contrario, según señala la norma, si la información visual hace que el efecto sonoro sea redundante, no debe describirse el sonido; por ejemplo, indicar "(Aplausos)" cuando hay en pantalla un plano del público aplaudiendo. En 
este sentido, se deben subtitular los efectos sonoros que sean necesarios para un buen seguimiento de la trama argumental.

Tras el análisis se constata que no todas las películas indican los efectos sonoros. Por otra parte, en las que se especifica se ha observado una diferencia por países en la posición de los subtítulos, como ya se ha adelantado en un apartado anterior. En los filmes con la modalidad UGH alemán, los efectos sonoros se muestran mediante texto centrado en la parte inferior de la pantalla, al igual que el resto de subtítulos, por ejemplo, en Lady Halcón (1985) [Donnern], [Glocke lautet], (imagen 18). Asimismo, en el SPS español, las anteriores a la norma UNE 153010:2012, lo marcan con subtítulos centrados en la parte inferior de la pantalla, como se ven en Chicken Run: Evasión en la Granja (2000) (imagen 19), La lengua de las mariposas (1999) y La gran aventura de Mortadelo y Filemón (2003).
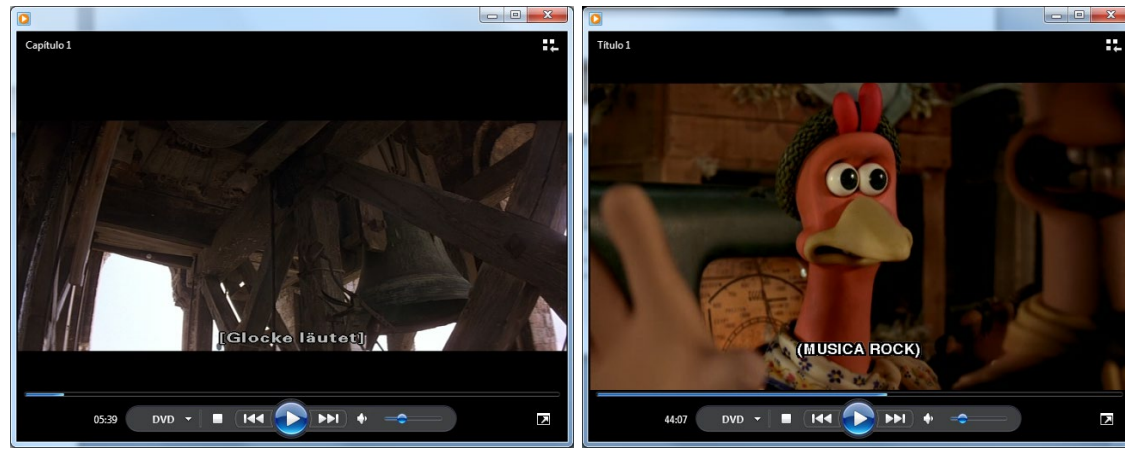

Imagen 18: Lady Halcón (1985)

Imagen 19: Chicken Run: Evasión en la Granja (2000)

Sin embargo, en El Increíble Hulk (2008) y las películas más actuales se suele ubicar esta información en la parte superior derecha. Es el caso de El malvado zorro feroz (2017) y Campeones (2018). tal y como marca la norma UNE 153010:2012 "cuando un sonido se considere efecto sonoro su subtítulo debe ubicarse en la parte superior derecha, siempre que sea técnicamente posible" (p. 8) ${ }^{30}$. Otras recientes, en cambio, indican los efectos sonoros en

30. Aspecto ya recogido en la norma UNE 153010:2003:13. 
la parte inferior de la pantalla, ya sean centrados, como en El olivo (2016) y Las aventuras de Tadeo Jones (2012), o posicionados a la derecha, como se muestran en el filme Dos mujeres (2017).

Tampoco hay uniformidad en el formato de los subtítulos de los efectos sonoros. En la versión UGH alemán suelen aparecer entre paréntesis y mayúsculas (HAHN KRÄHT), (HANDY KLINGELT), (TELEFON KLINGELT), (TÜR SCHLIEßT SICH) ${ }^{31}$. En España observamos una mayor variación, la norma UNE 153010:2012:13 especifica que los efectos sonoros deben indicarse "entre paréntesis y con la primera letra en mayúscula y las demás minúscula", como vemos en El malvado zorro feroz (2017) (Imagen 20): (Martillazos), (Trinos), (Golpe). En la película Campeones (2018), sin embargo, la información aparece en corchetes y todo ello en minúsculas (Imagen 21): [sirena], [vítores], [ambiente estadio]. En otras películas se muestran los efectos sonoros entre paréntesis, pero el texto en mayúsculas, como en El Increible Hulk (2008), por ejemplo: (MÚSICA ROMÁNTICA), (ALARMA PULSÓMETRO), (ALARMA ORDENADOR).
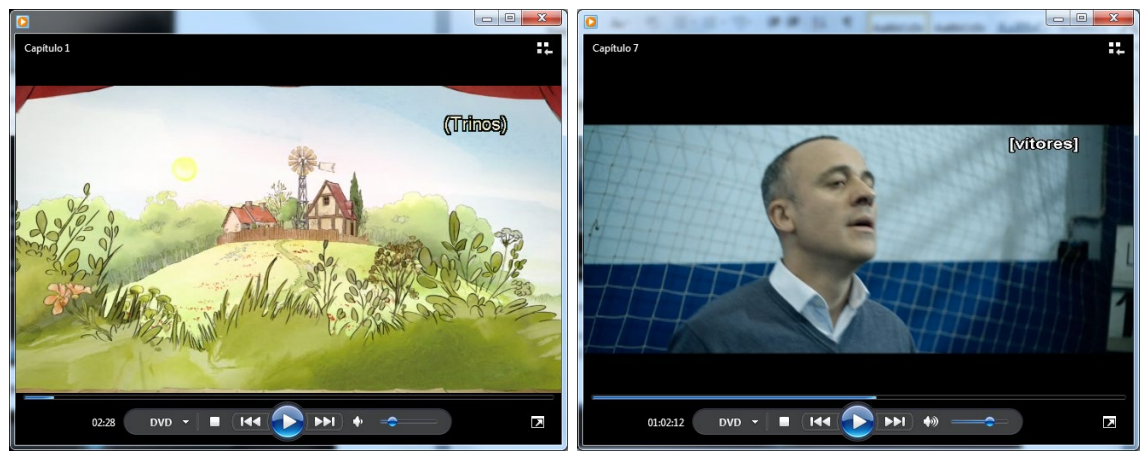

Imagen 20: El malvado zorro feroz (2017) Imagen 21: Campeones (2018)

En cuanto a los parámetros "música" y "canciones", la norma UN2012: 15-16 subraya que se debe subtitular la música y la letra de las canciones "si es importante para ayudar al espectador a comprender la trama", utilizando uno o más de estos tres contenidos: tipo de música, sensación que transmite e identificación de la pieza (título, autores, etc.). En lo que respecta a la 
música, debería seguir el formato de un efecto sonoro, es decir, en la parte superior derecha, entre paréntesis, la primera letra en mayúsculas y el resto en minúsculas. Por otra parte, en las directrices en lengua alemana se propone el asterisco para marcar los ruidos y la música, y la almohadilla para la letra de las canciones, como veremos a continuación (UTE2013, FFA2017 y MDR2018, en esta última fuente se recoge el ejemplo "*Lied auf Spanisch*, *Lied auf Spanisch:/ Julio Iglesias "La Paloma"*, p. 21). Sin embargo, en las películas analizadas con el subtitulado UGH alemán no se han empleado en ninguna de ellas los símbolos asterisco ni almohadilla.

Tras el análisis, se concluye que la tendencia es especificar el tipo de música que aparece, como encontramos ya en algunas de las obras cinematográficas más antiguas, Lady Halcón (1985), con indicaciones del tipo: [fröhliche Musik in der Ferne], [Umheimliche Instrumentalmusik], [Schnelle Instrumentalmusik], [Thriumphale Instrumentalmusik], [Bedrohliche Instrumentalmusik], [Sanfte Instrumentalmusik], detallándose igualmente la información contextual: [Schaurige Kirchengesang hallt durch den Tunnel], [Fröhliche Musik in der Ferne]. También se marca en las más actuales: Batman y Harley Quinn (2017): [PUNKMUSIK] [TITELMUSIK]. En español, por ejemplo, en Chicken Run: Evasión en la Granja (2000) (MÚSICA DE INTRIGA), (MÚSICA DE ACCIÓN), (MÚSICA TRISTE), (MÚSICA ROCK) y en Dos mujeres (2017) (Música suave).

En el caso de la película con UGH alemán Tom y Jerry: El anillo mágico (2002), donde no hay apenas diálogo y la música ambiente es fundamental, se indica muy al detalle el tipo de música instrumental, dependiendo del momento, señalando más de diez tipos distintos: [Schnelle Instrumentalmusik], [Kämpferische Instrumentalmusik], [Sanfte Instrumentalmusik], [Trostlose Instrumentalmusik], [Fröhliche Instrumentalmusik], [Optimistische Instrumentalmusik], [Instrumentale Sambamusik], [Gemütliche Instrumentalmusik], [Triumphierende Instrumentalmusik], [dramatische, schnelle Instrumentalmusik], [Unbeschwerte Instrumentalmusik], etc. En efecto, estos matices aportan información relevante para la trama a la persona sorda o con discapacidad auditiva.

En cuanto a las canciones, la norma establece que se debería subtitular la letra de las canciones usando el símbolo de una nota musical o almohadilla al principio de cada subtítulo de la canción y, en el subtítulo final, una de 
inicio y otra de cierre, siguiendo el formato de un efecto sonoro, es decir, en la parte superior derecha, entre paréntesis, la primera letra en mayúsculas y el resto en minúsculas (UNE 153010:2012:15). En referencia a las directrices en lengua alemana, también se sugiere la almohadilla en UTE2013 y en FFA2017.

En algunas películas se ha marcado el tipo de canción, identificando autor y título (o solo título) tanto en el subtitulado en español como en alemán, tal y como se ve en el ejemplo de Batman y Harley Quinn (2017) (centrado en parte inferior y en mayúsculas, imagen 22) y Campeones (2018) (parte superior derecha, imagen 23):
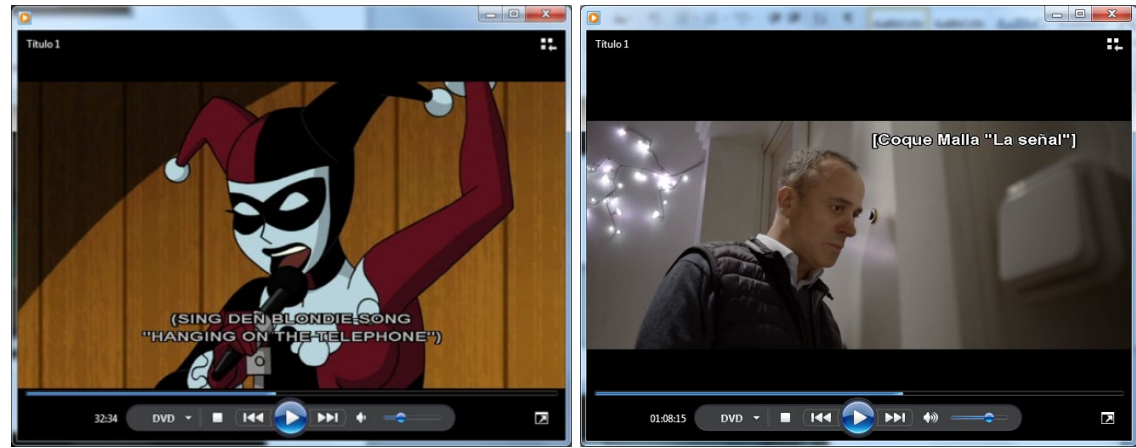

Imagen 22: Batman y Harley Quinn (2017)

Imagen 23: Campeones (2018)

Se ha observado que, en general, en la transcripción se marca el texto de la canción en cursiva. ${ }^{32}$ En las películas musicales o con alto contenido de canciones en el guion, como Tom y Jerry: Charlie y la Fábrica de Chocolate (2017), y Tom y Jerry: Robin Hood y el ratón de Sherwood (2012), en las que en muchos momentos los personajes se expresan cantando, se transcriben los textos cantados y se indican en cursiva y a veces, además, con etiqueta, como observamos en la imagen 24. El símbolo de la almohadilla aparece en la transcripción de la canción en el filme Dos mujeres (2017), dejándose la letra

32. En Lili Marleen (1981) se transcribe la letra cuando se la ve a la protagonista cantando esta canción y se marca con el color que la identifica (cian), sin cursiva. 
en francés sin traducir y manteniéndose así la trama en contexto extranjero, también para el espectador con discapacidad auditiva (imagen 25).
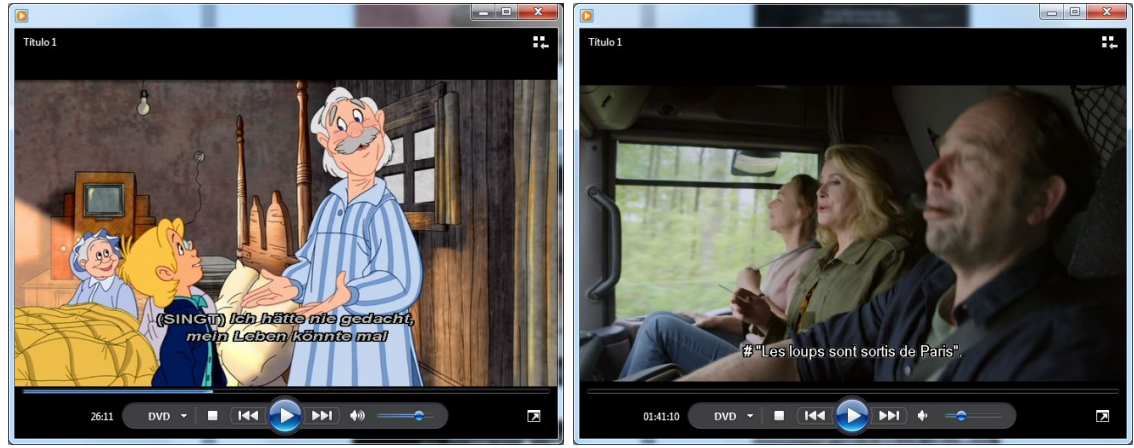

Imagen 24: Tom y Jerry: Charlie y la Fábrica de Chocolate (2017) Imagen 25: Dos mujeres (2017)

El marcado de las canciones en SPS español se suele indicar con etiqueta y cursiva, como ya se ha señalado, pero igualmente se especifica con el símbolo de una nota musical y sin cursiva en el caso de Campeones (2018, imagen 26) o entre corchetes angulares y etiqueta, y todo ello sin cursiva, tal y como aparece en La gran aventura de Mortadelo y Filemón (2003, imagen 27).
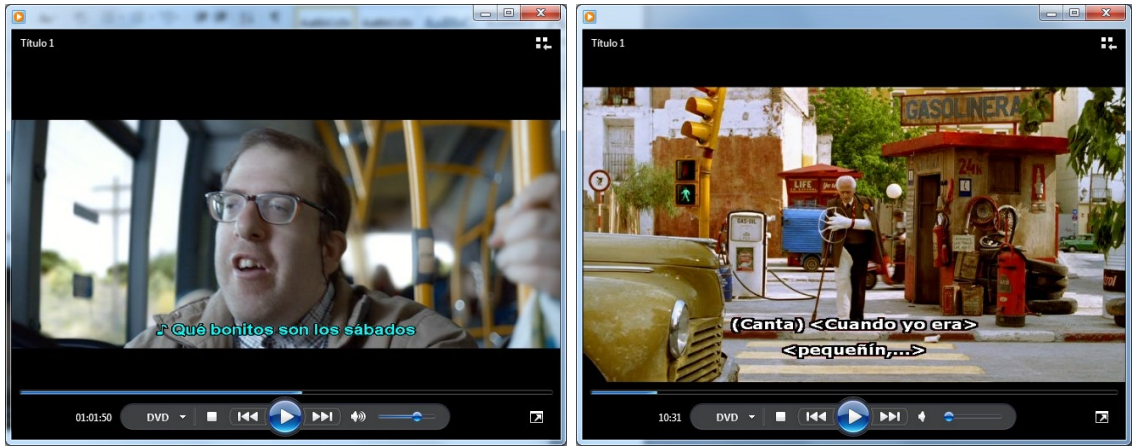

Imagen 26: Campeones (2018)

Imagen 27: La gran aventura de Mortadelo y Filemón (2003) 
En definitiva, en cuanto a estos parámetros, no hay uniformidad en el formato en ninguna de las lenguas, pero sí hemos observado cierta evolución en su tratamiento a lo largo de estas últimas décadas. Desde el punto de vista diacrónico, la tendencia es que las obras más actuales marquen más detalladamente los efectos sonoros y la música ambiente.

\subsection{Otra información}

Con el término "Información contextual" se hace referencia a una serie de elementos suprasegmentales, sonidos vocales (exceptuando el habla y atribuible a uno o varios personajes) e indicadores de forma o cantidad que, añadidos al texto, proporcionan detalles sobre cómo comunican los hablantes (norma UNE 153010:2012: 6). La especificación de los elementos suprasegmentales debe aparecer justo delante del texto al que se aplica. En cuanto a su formato, según la norma UNE 153010:2012: 14 debe presentarse en mayúsculas y entre paréntesis (IRÓNICO); según las directrices alemanas MDR2018:15, el texto ser marcaría en minúsculas: (ironisch).

Precisamente es en este parámetro en el que se observa una mayor evolución en su tratamiento a lo largo de estas décadas. En lo que respecta a la modalidad UGH alemán, a excepción de la película Lady Halcón (1985), que contiene información contextual bastante detallada, en las películas más antiguas analizadas, en general, no hay información contextual o muy poca (Tom y Jerry: El anillo mágico (2002) [Dümmliches Kichern], [Freddie und Joey knurren bedrohlich], [Tom kichert dümmlich]). Las más actuales son las que aportan una mayor información contextual, marcando, por ejemplo, el estado anímico del personaje que habla, por ejemplo, el perro ScoobyDoo que tartamudea de miedo al ver en escena a la diabólica Drella, a quien confunde con un vampiro (imagen 28), o el personaje de Tadeo Jones, que tímidamente se dirige a la azafata (imagen 29). 

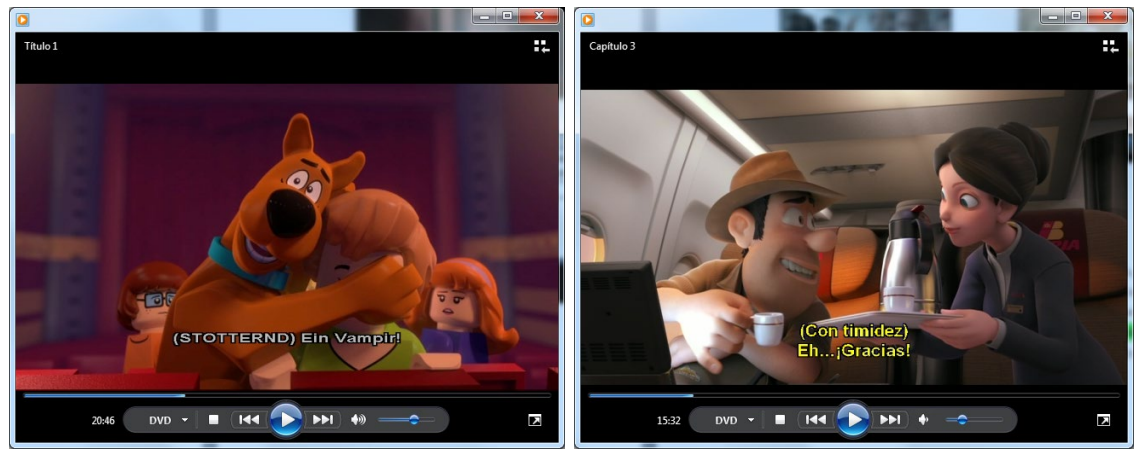

Imagen 28: Scooby-Doo (2016)

Imagen 29: Las aventuras de Tadeo Jones (2012)

Asimismo, en los filmes más recientes se encuentra el uso de guiones para indicar en la misma imagen dos tipos distintos de información: por un lado, la transcripción del diálogo y, por otro, información contextual en mayúsculas y entre paréntesis (imágenes 30 y 31 ):
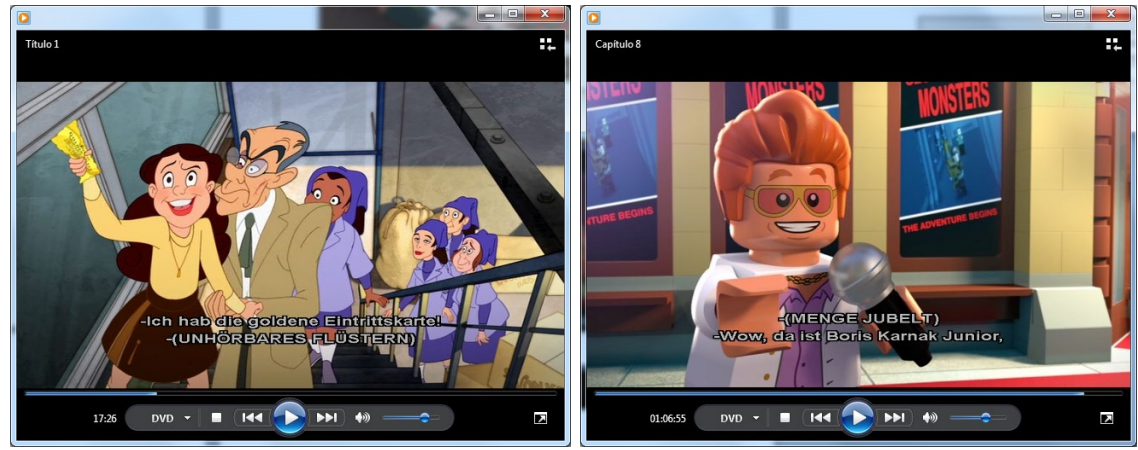

Imagen 30: Tom y Jerry: Charlie y la Fábrica de Chocolate (2017) Imagen 31: Scooby-Doo (2016)

En referencia al parámetro "Otras lenguas", la norma UNE 153010:2012 no establece una pauta concreta a la hora de señalizar el uso de una lengua extranjera en esta modalidad de subtitulado (Hurtado Malillos 2017), ni tampoco se observa en las directrices en lengua alemana. En las películas 
analizadas, el empleo de una segunda lengua ha sido esporádico y se ha marcado en las que tenía presencia con una etiqueta que indicaba la atribución: (IN FREMDSPRACHE), (AUF FRANZÖSISCH), (AUF INDISCH) en la obra La princesita (1995, imagen 32), así como en Tom y Jerry: Charlie y la Fábrica de Chocolate (2017, imagen 33) con la etiqueta (SPRICHT FRANZÖSISCH), o en El increíble Hulk (2008), donde leemos: (Habla en inglés) (Habla en portugués).
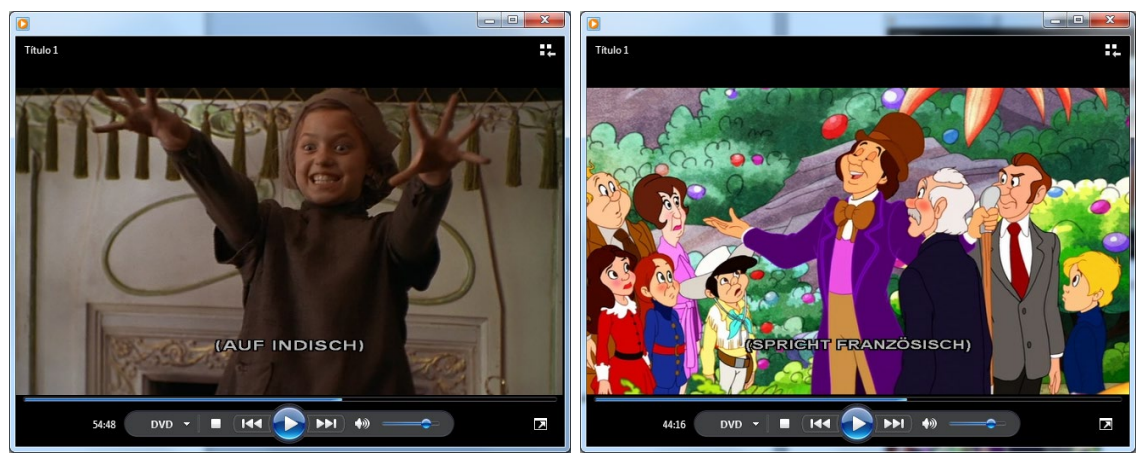

Imagen 32: La princesita (1995)

Imagen 33: Tom y Jerry: Charlie y la Fábrica de Chocolate (2017)

En otros casos se ha incluido el texto en la lengua origen como un guiño de extranjerización en el guion de la película: “¡Excuse-moi, Monsieur Dufarge!” (La princesita, 1995) y “¡Ay, caramba!” (Tom y Jerry: Charlie y la Fábrica de Chocolate, 2017) (sobre el tratamiento del multilingüismo en traducción audiovisual cfr. Hurtado Malillos; Cuéllar Lázaro 2018).

\section{Conclusiones}

Desde una perspectiva diatópica, los resultados del análisis ponen de relieve que esta variante de subtitulado en los dos contextos estudiados, el alemán y el español, manifiesta diferencias sustanciales en algunos de los parámetros. Con respecto a la identificación de los personajes, la variante SPS español hace uso del color para diferenciar las intervenciones de los personajes mientras que la modalidad UGH alemán emplea solo el blanco (a excepción de la película Lili Marleen, 1981). Asimismo, se observa otra diferencia por países en 
cuanto a la posición de los subtítulos. En las películas en alemán, los efectos sonoros aparecen centrados en la parte inferior de la pantalla, como el resto de subtítulos. Sin embargo, en español, en las obras anteriores a la norma UNE 153010:2012 se indican con subtítulos centrados en la parte inferior de la pantalla, mientras que las más actuales suelen ubicarlo en la parte superior derecha. No obstante, esta especificación también se ha hallado en la parte inferior derecha, lo que demuestra la falta de uniformidad en el uso.

Por otra parte, desde la perspectiva diacrónica, hay una tendencia en el subtitulado de las películas más recientes, en ambos países, a ser más exhaustivo en la referencia a los efectos sonoros y a un mayor detalle a la hora de indicar la información contextual, lo que contribuye a un mejor seguimiento de la trama argumental para la persona sorda o con discapacidad auditiva.

Desde nuestro punto de vista y con esta idea de base de normalizar la situación de consumo de un producto audiovisual, consideramos que igualmente debería especificarse, por ejemplo, la música que acompaña al comienzo o final de la película, aunque no sea fundamental para comprender la trama, porque de esta manera se le facilita a la persona sorda o con discapacidad auditiva una información que tiene el resto de espectadores oyentes. ${ }^{33}$ En este sentido, sería deseable del mismo modo la inclusión de los subtítulos en todos los contenidos de los DVD: extras, comentarios, juegos interactivos, etc. Solo en algunos de los productos audiovisuales analizados se muestran los contenidos adicionales (o una parte de ellos) con subtítulos para sordos. ${ }^{34}$

A través del análisis se observa asimismo que no se ha conseguido aún una uniformidad en el formato de los subtítulos, ni tampoco una generalización de la calidad deseada, en ninguno de los dos países aquí considerados. Pero se puede concluir afirmando que se avanza en este camino y que, en España, el Curso de especialización en audiodescripción y subtitulación, con carácter

33. Esto se indica excepcionalmente en la película de 1985 Lady Halcón, en Tom y Jerry: El anillo mágico (2002) y en algunas de las más recientes, como Batman y Harley Quinn (2017) y El malvado zorro feroz (2017).

34. Entre ellos, Tom y Jerry: Charlie y la Fábrica de Chocolate (2017), Tom y Jerry: Robin Hood y el ratón de Sherwood (2012), el DVD de Batman y Harley Quinn (2017 y Escuadrón suicida 2018. De hecho, en los dos primeros aparece la siguiente aclaración en la contraportada del estuche del DVD: "Contenido Adicional/ Tráiler puede no estar codificado para sordos". 
nacional, podrá ayudar a aportar uniformidad y calidad a esta formación teniendo en cuenta la normativa vigente. Precisamente uno de los retos a los que se enfrenta la sociedad en el campo de la accesibilidad para personas sordas y con discapacidad auditiva es conseguir una subtitulación de acuerdo con los estándares de calidad existentes. En el caso de España, habrá que tener como referencia la norma UNE 153010:2012; en el contexto alemán, se aboga por elaborar una normativa que unifique las directrices existentes (UTE2013, FFA2017 y MDR2018). Sin lugar a duda, la calidad de este tipo de subtítulos repercutirá directamente en la recepción de la película por parte del espectador sordo o con discapacidad auditiva.

Tanto la legislación española como la alemana reconocen y defienden el derecho de las personas con discapacidad al acceso a la cultura y a las industrias creativas, pero desde los colectivos de discapacitados se subraya que las disposiciones normativas actuales siguen siendo "escasas y laxas" 35 . Por todo ello, habrá que seguir aunando esfuerzos para conseguir una mayor inclusión en la sociedad, de tal manera que también en este ámbito se garantice el ejercicio de los derechos de las personas con discapacidad sensorial.

\section{Referencias bibliográficas}

AENOR. (2003) Norma UNE 153010:2003. Subtitulado para personas sordas y personas con discapacidad auditiva. Subtitulado a través del teletexto. Madrid: Asociación Española de Normalización y Certificación (AENOR).

AENOR. (2012) Norma UNE 153010:2012. Subtitulado para personas sordas y personas con discapacidad auditiva. Madrid: Asociación Española de Normalización y Certificación (AENOR).

ARNÁrz UZQUIZA, Verónica. (2012) "Los parámetros que identifican el subtitulado para sordos. Análisis y clasificación.” MonTI 4, pp. 103-132.

CAmbra, Cristina; Nuria Silvestre \& Aurora Leal. (2008-2009) "Análisis de la comprensión por parte del alumnado sordo de los documentos televisivos subtitulados y criterios de mejora." Quaderns del CAC 31-32, julio 2008 junio 2009, pp. 155-159.

35. Cfr. Discapnet, El portal de las Personas con Discapacidad, Fundación ONCE. $<$ https://www.discapnet.es/actualidad/2019/02/el-cermi-reclama-al-congresouna-regulacion-legal-exigente-de-la-accesibilidad-al> 
CAMBra, Cristina; Nuria Silvestre \& Aurora Leal. (2013) "La interpretación de los adolescentes sordos y oyentes de un documental audiovisual: importancia del subtitulado." Revista de Logopedia, Foniatría y Audiología 33, pp. 99-108. CESyA. (2014) Memoria del Centro Español del Subtitulado y la Audiodescripción (CESyA) 2005-2013. Madrid: Real Patronato sobre Discapacidad.

CuÉllar LÁzaro, Carmen. (2016a) "El subtitulado para sordos en España y Alemania estudio comparado de los marcos normativos y la formación universitaria." Revista Española de Discapacidad (REDIS), 4:2, pp. 143-162.

CuÉllar Lázaro, Carmen. (2016b) "Proper Names in Audiovisual Translation. Dubbing vs. Subtitling. / Eigennamen in audiovisueller Übersetzung. Synchronisation vs. Untertitelung." Journal of Onomastics 107/108, pp. $117-134$.

CuÉllar LÁzARO, Carmen. (2018a) "Traducción accesible: Avances de la Norma española UNE 153010:2012.” Revista Ibero-Americana Pragensia XLVI:1, pp. 51-65 <https://doi.org/10.14712/24647063.2018.22>

CuÉllar LÁzaro, Carmen. (2018b) "El tratamiento de los dominicos en el cine: Peculiaridades en el subtitulado de películas multilingües." En: Bueno García, Antonio (ed.) 2018. Arte, religión y traducción. Comares: Colección Interlengua, pp. 327-339.

DíAz CinTAS, Jorge. (2007) "Por una preparación de calidad en accesibilidad audiovisual.” Trans II, pp. 45-49.

Díaz CinTAS, Jorge; Pilar Orero \& Aline Remael (eds.) (2007) Media for All. Subtitling for the Deaf, Audio Description and Sign Language. Amsterdam \& New York: Approaches to Translation Studies.

España. Ley 15/2001 de 9 de julio, de fomento y promoción de la cinematografía y el sector audiovisual. Boletín Oficial del Estado, 10 de julio de 2001, núm. 164, pp. 24904-24909.

España. Ley 27/2007, de 23 de octubre, por la que se reconocen las lenguas de signos españolas y se regulan los medios de apoyo a la comunicación oral de las personas sordas, con discapacidad auditiva y sordociegas. Boletín Oficial del Estado, 24 de octubre de 2007, núm. 255, pp. 43251 - 43259.

España. Ley 51/2003, de 2 de diciembre, de igualdad de oportunidades, no discriminación y accesibilidad universal de las personas con discapacidad. Boletín Oficial del Estado, 3 de diciembre de 2003, núm. 289, pp. 43187 - 43195. 
España. Real Decreto 1084/2015, de 4 de diciembre, por el que se desarrolla la Ley 55/2007, de 28 de diciembre, del Cine. Boletín Oficial del Estado, 5 de diciembre de 2015, núm. 291, pp. 115411-115432.

España. Real Decreto 94/2019, de 1 de marzo, por el que se establece el Curso de especialización en audiodescripción y subtitulación y se fijan los aspectos básicos del currículo. Boletín Oficial del Estado, 22 de marzo de 2019, núm. 70, pp. 29700-29729.

España. Orden CUD/426/2019, de 11 de abril, por la que se modifica la Orden ECD/2784/2015, de 18 de diciembre, por la que se regula el reconocimiento del coste de una película y la inversión del productor y la Orden CUD/769/2018, de 17 de julio, por la que se establecen las bases reguladoras de las ayudas previstas en el Capítulo III de la Ley 55/2007, de 28 de diciembre, del Cine, y se determina la estructura del Registro Administrativo de Empresas Cinematográficas y Audiovisuales. Boletín Oficial del Estado, 12 de abril de 2019, núm. 8, pp. 38501-38524.

FIAPAS. (2013) Investigación: Observatorio 'Universidad y Discapacidad'. Fundación Universia y CERMI (Comité Español de Representantes de Personas con Discapacidad). FIAPAS 146, pp. 22-23.

HELlebrand, Sabine. (2007) Untertitel für Hörgeschädigte im Fernsehen. Untersuchung einer 1:1-Untertitelung. Diplomarbeit Neuphilologische Fakultät. Tübingen: Eberhard-Karls-Universität.

HEZEL, Susanne. (2009) "Untertitelung für Hörgeschädigte für das deutsche Fernsehen: Vorgehensweisen, Forderungen, Richtlinien.” En: Nagel, Silke; Susanne Hezel; Katharina Hinderer \& Katrin Pieper (eds.) 2009. Audiovisuelle Übersetzung: Filmuntertitelung in Deutschland, Portugal und Tschechien. Frankfurt am Main: Peter Lang, pp. 147-264.

HurTado Malillos, Lorena. (2017) "Lenguas sin sonido. La representación del multilingüismo en el subtitulado para sordos. Un estudio aplicado." En: Bueno García, Antonio (ed.) 2017. II Curso Del Signo al Símbolo. La utilización de signos no verbales en la comunicación. Versión electrónica: <https://sites. google.com/view/signo/inicio?authuser $=0>$

HuRTADO Malillos, Lorena \& Carmen Cuéllar Lázaro. (2018) "El tratamiento del multilingüismo en traducción audiovisual: el caso del cine de animación infantil y juvenil." Skopos 9, pp. 107-136.

IZARD, Natalia. (2001) "La subtitulación para sordos del teletexto en Televisión Española." En: Lorenzo, Lourdes \& Ana Pereira (eds.) 2001. Traducción 
subordinada inglés-español/galego II: el subtitulado. Vigo: Universidade de Vigo, pp. 169-194.

LoRENZO, Lourdes \& Ana Pereira. (2011) "Deaf children and their access to audiovisual texts: school failure and the helplessness of the subtitler." En: Di Giovanni, Elena (ed.) 2011. Entre texto y receptor: Accesibilidad, doblaje $y$ traducción / Between text and receiver: accessibility, dubbing and translation. Frankfurt am Main: Peter Lang, pp. 185-201.

LORENZO, Lourdes \& Ana Pereira. (2012) "Subtitulado para sordos: un reto y una necesidad: pasado, presente y futuro del SPS en España." En: Martínez Sierra, Juan José (coord.) 2012. Reflexiones sobre la traducción audiovisual. Tres espectros, tres momentos. Valencia: Universitat de Valencia, pp. 109-123. Matamala, Anna; Pilar Orero (eds.) (2010) Listening to Subtitles: Subtitles for the Deaf and Hard of Hearing. Frankfurt am Main: Peter Lang.

MÉAN, Yves-Manuel. (2011) Einheitliche Untertitel für Hörgeschädigte im deutschsprachigen Fernsehen - Chance oder Utopie? Ein Vergleich der Untertitelungsrichtlinien in Deutschland, Österreich und der Schweiz. Masterarbeit. Zürcher Hochschule für Angewandte Wissenschaften. Versión electrónica: <http://sonosinfo.ch/media/3992257c2ed2ebb3ffff8034ffffffd2. pdf $>$

Melgarejo WeinandT, Claudia. (2005) Untertitelung für Hörgeschädigte in Frankreich und Deutschland - ein Vergleich. Doktorarbeit. Ruprecht-KarlsUniversität Heidelberg.

NAGEL, Silke; Susanne Hezel; Katharina Hinderer \& Katrin Pieper (Hrsg.) (2009) Audiovisuelle Übersetzung: Filmuntertitelung in Deutschland, Portugal und Tschechien. Frankfurt am Main: Peter Lang.

NEVES, Josélia \& Lourdes Lorenzo. (2007) "La subtitulación para s/Sordos, panorama global y prenormativo en el marco ibérico." Trans. Revista de traductología 11, pp. 95-114.

PANIER, Anne; Kathleen Brons; Annika Wisniewski; Marleen Weißbach. (2012) Filmübersetzung Probleme bei Synchroni-sation, Untertitelung, Audiodeskription. Frankfurt: Leipziger Studien zur angewandten Linguistik und Translatologie. PARDINA I MUNDÓ, Joaquím. (1998) "El futuro de la subtitulación para personas sordas o con pérdidas auditivas." Versión electrónica: <http://www.terra.es/ personal6/932108627/Articulos/arti3-C.htm>

Pardina i Mundó, Joaquín. (2000) Estudio sobre el Servicio Audiovisual de Subtitulación para personas sordas o con pérdidas auditivas en el mercado 
televisivo español. Dirección Audiovisual de la CMT. Versión electrónica: <http://www.terra.es/personal6/932108627/Articulos/arti3-C.htm>

Pereira Rodríguez, Ana. (2005) "El subtitulado para sordos: estado de la cuestión en España." Quaderns. Revista de traducció 12, pp. 161-172.

ReMAEL, Aline; Pilar Orero \& Mary Carroll (eds.) (2012) Media for All: Audiovisual Translation and Media Accessibility at the Crossroads. Amsterdam: Rodopi.

Romero-Fresco, Pablo. (2015) "Cine accesible: uniendo los puntos entre la traducción audiovisual y la realización cinematográfica." Prosopopeya: revista de crítica contemporánea I:9, pp. 163-191.

RÜNGS, Maren. (2006) Kommunikation ohne Barrieren? Eine empirische Untersuchung zur Fernsehnutzung Hörgeschädig-ter. Hausarbeit zur Erlangung des Grades einer Magistra Artium der Philosophischen Fakultät der Westfälischen Wilhelms-Universität Münster, Münster. Versión electrónica: <http://www.uni-muenster.de/Kowi/bibliothek/archiv/r.html>

SCHNEIDER, Bernd. (2011) Untertitelarbeitsgruppe in Zusammen-arbeit mit SignDialog. Versión electrónica: <http://signdialog. de/wpcontent/2011/UT_ Statistik_2005_bis_2011.pdf>

SZARKOWSKA, Agnieszka; Jagoda Zbikowskab \& Izabela Krejtz. (2013) "Subtitling for the deaf and hard of hearing in multilingual films." International Journal of Multilingualism 10:3, pp. 292-312.

TAlavÁN Zanón, Noa; Tomás Costal Criado; José Javier Ávila. (2016) Traducción y accesibilidad audiovisual. Universitat Oberta de Catalunya.

TORRES MOnREAL, Santiago; Rafael Santana Hernandez. (2005) "Reading levels of Spanish deaf students." American Annals of the Deaf 150:4, pp. 379-87.

UtraY, Francisco; Ana Pereira \& Pilar Orero. (2009) "The Present and Future of Audio Description and Subtitlingfor the Deaf and Hard of Hearing in Spain." Meta 54:2, pp. 248-263. Versión electrónica: <http://id.erudit.org/ iderudit/037679ar>

\section{Filmografía}

Batman y Harley Quinn (2017), EEUU, Sam Liu. [UGH]

Campeones (2018), España, Javier Fesser. [SPS]

Chicken Run: Evasión en la Granja (2000), Reino Unido, Peter Lord y Nick Park. [SPS]

Dos mujeres (2017), Francia/Bélgica, Martin Provost. [SPS]

Escuadrón suicida (2018), EEUU, Sam Liu. [UGH] 
El Increíble Hulk (2008), EEUU, Louis Leterrier. [UGH]

El malvado zorro feroz (2017), Francia/Bélgica, Benjamin Renner y Patrick Imbert. [SPS]

El olivo (2016), España, Iciar Bollain. [SPS]

Gremlins (1984), EEUU, Joe Dante. [SPS]

La gran aventura de Mortadelo y Filemón (2003), España, Javier Fesser. [SPS]

La lengua de las mariposas (1999), España, José Luis Cuerda. [SPS]

La princesita (1995), EEUU, Alfonso Cuarón. [UGH]

Lady Halcón (1985), EEUU, Richard Donner. [UGH]

Las aventuras de Tadeo Jones (2012), España, Enrique Gato. [SPS]

Lili Marleen (1981), West Germany, Rainer Werner Fassbinder. [UGH y SPS]

Scooby-Doo (2016), EE UU, Rick Morales. [UGH]

Tom y Jerry: Charlie y la Fábrica de Chocolate (2017), EEUU, Spike Brandt. [UGH] Tom y Jerry: El anillo mágico (2002), EEUU, James Tim Walker. [UGH]

Tom y Jerry: Robin Hood y el ratón de Sherwood (2012), EEUU, Spike Brandt y Tony Cervone. [UGH]

\section{NOTA BIOGRÁFICA / BIONOTE}

CARMEn CuÉllar LÁZARO se doctoró en la Friedrich-Schiller Universität Jena, Jena (Alemania), institución en la que compaginó docencia e investigación. Posteriormente fue Profesora Titular en la Facultad de Traducción e Interpretación de la Universidad de Valladolid, donde desempeñó a su vez el cargo de Secretaria Académica. En la actualidad es directora del Departamento de Filología Francesa y Alemana en la Facultad de Filosofía y Letras. Ha realizado distintas estancias de estudio e investigación en universidades de Alemania, Austria y Reino Unido. Asimismo, ha participado en varios proyectos de investigación e innovación financiados y ha publicado numerosos capítulos de libros y artículos en revistas de carácter internacional. Forma parte del Grupo de Investigación de Excelencia de la UVa ITNT (Intersemiótica, Traducción y Nuevas Tecnologías), y es miembro de varios comités científicos de revistas internacionales, así como de la prestigiosa institución alemana Deutscher Akademischer Austauschdienst (DAAD). 
CARMen CuÉllar LÁzARo defended her doctoral thesis at the FriedrichSchiller Universität Jena, Jena (Germany). As a research assistant at the institution, she combined research and teaching. Later she was a tenured professor in the Department of Translation and Interpretation at the Universidad de Valladolid (Spain), where she also served as the Academic Secretary. She is currently Director of the Department of French and German Philology at the Faculty of Philosophy and Letters. She has participated in different study and research opportunities at universities in Germany, Austria, and the United Kingdom. She has also worked on various funded research and innovation projects and has published numerous book chapters and articles in international journals related to her fields of research. She is a member of the Excellence Research Group (Grupo de Investigación de Excelencia) of the Universidad de Valladolid ITNT (Intersemiotics, Translation and New Technologies) and of several scientific committees of international journals, such as of the prestigious German Institution Deutscher Akademischer Austauschdienst (DAAD). 